\title{
A Critical Analysis of the Solvency II Proposals
}

\author{
René Doff \\ Financial Management, Twente University, PO Box 217, Enschede 7500 AE, Netherlands. \\ E-mail: rene.doff@gmail.com
}

The European Commission has recently published the Solvency II proposals with the objective to fundamentally review the insurance supervisory framework. We test the Solvency II framework against seven criteria developed by Cummins et al. describing how best to duplicate the operation of an efficient and complete market. We conclude that Solvency II satisfies most of these criteria. We recommend a more balanced framework between Pillar I and II/III. In this way, Pillar II/III will resolve some of the problems in Pillar I, such as inappropriate incentives of the capital requirements formulae (hard solvency capital requirement limit, modular minimum capital requirement). Areas for further work on Pillars II and III are operational and business risk, long-term effects of strategic decision-making.

The Geneva Papers (2008) 33, 193-206. doi:10.1057/gpp.2008.2

Keywords: insurance supervision; risk management; Solvency II

\section{Introduction}

The rationale of insurance regulation is often related to market imperfections such as agency problems and costly information. ${ }^{1}$ Agency problems refer to the incentive discrepancy between the insurance firm's owners (and managers) on one side and policyholders on the other. In an agency problem, there is an information asymmetry between the two parties. This asymmetry can be resolved by acquiring and distributing more information, but this has a certain cost. Based on these problems, various forms of insurance regulation have existed since the mid-1800s. It is generally accepted that insurance regulation should be designed to duplicate as closely as possible the outcome of a competitive market. ${ }^{2}$ One of the elements of an efficient and competitive market is that all market participants have access to relevant information. To that end, one of the regulatory measures aims for more market discipline by requiring the disclosure of sufficient risk management information to the market. Other relevant supervisory instruments are licensing procedures, supervision and monitoring and capital requirements. ${ }^{3}$ Sijben $^{4}$ concludes that the so-called Structured Early Intervention and Resolution process that is the basis of Pillars II and III is much more stable and efficient than sole capital requirements. In this paper, we will focus on the supervision

\footnotetext{
${ }^{1}$ Klein (1995), Eling et al. (2007).

${ }^{2}$ Cummins et al. (1994).

${ }^{3}$ IAIS (2003).

${ }^{4}$ Sijben (2002).
} 
and capital requirements, as these are the elements covered in the European Solvency II framework.

The objective of this paper is to test the Solvency II framework against seven criteria for risk-based capital (RBC) requirements describing how best to duplicate the operation of an efficient and complete market. The criteria have been developed by Cummins et al. ${ }^{5}$ with the introduction of the RBC rules in the U.S. The remainder of this paper is organised as follows. The following section briefly introduces Solvency II. The penultimate section applies the criteria of Cummins et al. to Solvency II. Table 1 at the end of this section summarises the analysis and the last section concludes.

We will ignore in our paper the issues related to supervision of insurance groups. The Solvency II framework will have significant consequences for group supervision. However, the technical issues related to this deserve a separate paper in itself. Therefore, we prefer to leave them out of scope of the current paper.

\section{Solvency II regulations}

The Solvency II project aims to update the regulatory framework for insurance supervision in Europe. A key objective of the European Union is to come to a true single market. The original insurance rules date from the 1970s and the subsequent updates - called second and third generation insurance directives - focused on market convergence. ${ }^{6}$ They included coordination of regulatory and supervisory bodies and contained elements like single insurance licence principle and Europe-wide product offerings. Because the supervisory elements in the framework had become outdated, in the late 1990s the initiative was taken up to revise the insurance supervision regulations, in parallel with the Basel II developments in banking. The European Commission decided on a two-step approach, with Solvency I (which came into force in 2004) updating the outdated thresholds of the 1970s regime without changing the structure. Solvency II fundamentally reforms the supervisory structure and practice.

In parallel with the Solvency II process, a number of other initiatives have been taken to update various regulatory frameworks such as Internal Capital Assessment Standards (ICAS) in the U.K., ${ }^{7}$ the Swiss Solvency Test (SST) ${ }^{8}$ and the Financial Assessment Framework (FTK) in the Netherlands. ${ }^{9}$ Eling et al. and the CEA $^{10}$ provide an analysis of the various existing solvency systems. Also, the International Association of Insurance Supervisors (IAIS) started up various initiatives with the objective of convergence of the context of insurance solvency systems. Of these, Solvency II is the most important, because (1) it is a concrete legal framework rather than principles; (2) it will apply to a large and important insurance market (i.e.

\footnotetext{
${ }^{5}$ Cummins et al. (1994).

${ }^{6}$ KPMG (2002), Eling et al. (2007).

${ }^{7}$ FSA (2004).

${ }^{8}$ FOPI (2004).

9 DNB (2004).

${ }^{10}$ Eling et al. (2007) and CEA (2006).
} 
Europe). Solvency II will go into force in 2012 and the proposals were published in July 2007 by the European Commission.

Solvency II is based on the three-pillar framework that is also existent in Basel II. Pillar I focuses on financial requirements, such as market-consistent valuation of the balance sheet, including insurance liabilities and assets (and hence, the marketconsistent valuation of equity capital). In addition, Pillar I includes two capital requirements. The higher of the two is called the Solvency Capital Requirement (SCR) and will be calculated by either a standard approach or by internal models. The lower of the two is called the Minimum Capital Requirement (MCR). Breaching the MCR will trigger ultimate supervisory intervention (Solvency II, art. 136) and hence the MCR is the ultimate buffer to protect policyholder interests in case of an unwinding or run-off scenario. The SCR is a going-concern risk measure, targeting a 99.5 per cent Value-at-Risk. The standard approach to the SCR is a set of one-size-fits-all formulae that could be applied by all insurers, irrespective of size, portfolio mix and geographical location. Insurers could, however choose to develop an internal model that better fits their risk profile, with the outcomes subject to supervisory approval. A similar philosophy is implemented in Basel $\mathrm{II}^{11}{ }^{11}$ as an incentive for companies to improve their risk management practices. At the moment of writing, the focus of Solvency II has been on the standard approach with the internal models criteria only briefly discussed, for example, in Consultative Paper $20 .^{12}$

The SCR is based on four major risk categories: market risks, credit risks, operational risks and underwriting risks. Each of these categories is further subcategorised as indicated by the International Association of Actuaries (IAA). ${ }^{13}$ The standard approach of Solvency II includes a formula for each of these risk subtypes, in total at least 20 formulae. ${ }^{14}$ The formulae are either based on a factorbased approach (e.g. the premium risk within non-life underwriting risks) or a scenario-based approach (e.g. equity risk within market risks). ${ }^{15}$

\section{A critical analysis of Solvency II}

In this section, we analyse the foreseen Solvency II framework ${ }^{16}$ using the seven criteria as set out in Cummins et al. ${ }^{17}$ For each criterion, we analyse key elements of the Solvency II framework. The criteria are based on the philosophy that "solvency regulation should be designed to duplicate as closely as possible the outcome of a

\footnotetext{
${ }^{11}$ Basel Committee on Banking Supervision (2004).

12 CEIOPS (2007b).

${ }^{13}$ IAA (2004).

14 CEIOPS (2007a).

15 Ibid.

${ }^{16}$ It should be noted that the Solvency II framework is not yet final. Some parts have been published by the European Commission and are for final decision-making. In this political process, elements could be added to or changed in the framework. Also, some parts of Solvency II, such as Pillars II and III elements have not been discussed in-depth at all. They will need further design choices. We rely as much as we can on existing proposals and texts.

${ }^{17}$ Cummins et al. (1994).
} 
competitive market in which all parties have access to all relevant information". The authors emphasise that a supervisory framework should focus on resolving information asymmetries and the cost of insurance solvencies for the economy. This is explicitly different from an objective to avoid any insurance insolvency. The authors found that, of about 300 insurance guarantee fund assessments in the period 19691990, about 80 per cent of the amounts were caused by the 25 largest failures. Hence the potential for insolvency costs for the economy is much higher for larger companies despite the higher potential (probability) of failure for smaller firms. We note that for Solvency II most of the progress so far has been made in the area of Pillar I, whereas next steps can be achieved in Pillars II and III. This focuses on decreasing the information asymmetry between stakeholders.

\section{The risk-based capital formula should provide incentives for weak companies to hold} more capital and/or reduce their exposure to risk without significantly distorting the decisions of financially sound insurers

It is important that a supervisory framework includes the appropriate incentives. This is not the case in the current Solvency I rules, where important risks are ignored and the solvency requirements could conflict with good risk management. ${ }^{18}$ The Solvency II capital requirements laid out in the SCR is to be risk-based: the higher the risk profile of the company, the higher the SCR. For the standard approach, most relevant risks are present in the capital requirements (see criterion 2 below).

Under Solvency II, the incentives for financially weak and sound insurers are equal: companies are encouraged to manage their risks, value their liabilities using economic principles and keep adequate capital to absorb risks. Whether these incentives will trigger different behaviour depends on whether capital is binding (i.e. whether the available capital approaches the SCR). And this is exactly the effect of criterion 1 . Hence, Solvency II aims to satisfy criterion 1.

In the standard approach, most risk charges are truly risk-based using scenarios such as market risks where firms are required to apply a market shock to their balance sheet. For example, firms are required to determine the effects of a 32 per cent decrease in global equity markets. ${ }^{19}$ The scenarios are prescribed, but the effects may differ from company to company depending on the risk exposure. This makes the scenario approach risk-sensitive and risk-specific. Other risk charges are partly based on factors such as health and non-life underwriting risks, ${ }^{20}$ where the risk charge is based on a prescribed factor and a volume measure such as premiums. The major advantage of a factor-based approach is its simplicity, which makes it easy to apply for a wide range of companies, but this comes at the cost of decreased risk-sensitivity. Also, riskmitigating measures (e.g. reinsurance) are not fully taken into account. The scenariobased components create the right incentives for weak companies, that is, by improving their solvency position by reducing their risk exposure or holding more

\footnotetext{
${ }^{18}$ CEA (2007).

${ }^{19}$ CEIOPS (2007a, pp. 42-44).

${ }^{20}$ Ibid., pp. $73-85$.
} 
capital. The factor-based components are less risk-based, because a reduction in capital requirements is achieved by reducing the size rather than the risk profile. Also, risk-mitigating effects are not recognised. This may lead to risk-seeking behaviour for non-life insurers with inadequate capital resources. Hence, the standard approach does not create appropriate incentives for non-life and health insurers, especially for the financially unsound ones. This means that there is a clear role for Pillars II and III as indicated by Sijben. ${ }^{21}$

For those companies that use internal models to determine the SCR, it can be assumed that these internal models measure the risks accurately. Generally, such a system would include the appropriate incentives to manage the risks. This is especially true because one of the conditions to apply internal models is that the model is truly embedded in the management process of the company, that is, managers make business decisions based on the outcomes of the internal model. Because management and supervisory objectives are aligned, incentives are aligned as well and hence the agency problem has decreased. An important safeguard in the internal models approach is that the supervisor needs to approve them. What the exact requirements on internal models will be is at this moment still unclear. It is known that the U.K. supervisor frequently overrides the outcomes of the internal model in the ICAS regime. $^{22}$ It is, however, unclear what the exact rationale for this is. Under the Solvency II regime, supervisors will have similar powers to apply a capital add-on, but they are meant to be "... neither routinely nor commonly applied...". 23 If the supervisor would, however, apply capital add-ons too easily, then inappropriate incentives could arise. We are, however, optimistic and believe that the internal model approach is likely to satisfy criterion 1 .

There is a debate between various stakeholders on whether the SCR should be a "hard limit" or an "important target" value. In other words: how strongly will supervisors intervene if an insurance company breaches the SCR? And additionally: will breaches always need to be publicly disclosed or will temporary breaches remain private between the company and the supervisor? If supervisors respond strongly to even a minor breach of SCR or require the breach to be publicly disclosed, then companies will have an incentive to hold more capital than the required SCR. There is an incentive to hold more capital than a 99.5 per cent Value-at-Risk. Whether this is contrary to the underlying economics of the insurance market depends on the definition of "weak" and "financially sound". In the Framework for Consultation, the European Commission has chosen to calibrate the SCR at a 99.5 per cent Value-atRisk. We assume that this implies that the 99.5 per cent Value-at-Risk is the threshold for "financially sound" companies. If companies had an incentive to operate far above that threshold, they would hold too much capital, which would create a nonoptimal insurance industry. ${ }^{24}$ After all, if capital is intended as a buffer to absorb risks, it should be allowed to use the buffer when risks materialise. As a result, too

\footnotetext{
${ }^{21}$ Sijben (2002).

${ }^{22}$ FSA (2005).

${ }^{23}$ CEIOPS (2007b).

${ }^{24}$ Sijben (2002).
} 
strong interventions as a response to SCR breaches create inappropriate incentives. It would be preferable to use the SCR as an important target value and support this by Pillar II measures.

The MCR represents a capital threshold that triggers ultimate supervisory intervention. This means that this amount should be truly risk-based. At the same time, the trigger for ultimate supervisory intervention should be extremely clear to both supervisors and the supervised insurers. To that end, it should be objective and very simple to calculate. The QIS3 proposals include two approaches for the MCR. ${ }^{25}$ The so-called "modular approach" consists of three capital charges (market and underwriting risks) with each component being calculated using a very simple factor-based approach. ${ }^{26}$ This might be a little too simplistic, because for instance the duration mismatch is not addressed in the market risk MCR formulae. Also, the MCR formula for underwriting non-life risks resembles the current Solvency I formulae. Hence, they are not risk-based at all. The modular approach does not satisfy criterion 1.

In the so-called "compact approach", the MCR is calculated as a percentage of an approved SCR (e.g. 30 per cent). This means that the supervisory approved SCR - a risk-based variable - is used to set a threshold for ultimate supervisory intervention. The potential advantage of the compact approach is the direct relation between SCR and MCR. Opponents argue that the SCR might include some subjective and company-specific elements. Those in favour argue that such an argument undermines the entire Solvency II system being built on a Value-at-Risk basis. Also, they point to the fact that the SCR should be approved by the supervisor. This should be a clear sign that a supervisor agrees with the calculated SCR. If the supervisor agrees to that number, there is no conceptual reason why the SCR should not be used as a basis to set the MCR. The main advantage of the compact approach is that for a risk-based $\mathrm{SCR}$, the MCR is automatically risk-based. Also, the values automatically move in tandem. Hence this approach satisfies criterion 1.

\section{The risk-based capital formula should reflect the major types of risk that affect insurers and be sensitive to how these risks differ across insurers}

The objective of this criterion is to assess whether no important risk type is ignored in an $\mathrm{RBC}$ framework and to assess the risk-sensitivity. Capital requirements that are not sufficiently risk-sensitive will be less useful for supervisors to identify weak insurers from financially sound insurers. The importance of risk-sensitivity is also confirmed by the so-called "Sharma Report". ${ }^{27}$ After analysing 21 case studies of insurance failures and near-misses, the authors conclude that (1) financial problems are often caused by multiple risks rather than one isolated risk alone; and (2) internal controls and appropriate corporate governance structures are often more critical in avoiding

\footnotetext{
${ }^{25}$ CEIOPS (2007a).

26 Ibid.

${ }^{27}$ Ashby et al. (2003).
} 
failures than capital requirements. Both findings confirm the importance of risksensitivity in supervisory structures.

Solvency II includes capital requirements under Pillar I for market, credit, underwriting and operational risks. These risks are also addressed by $\mathrm{IAA}^{28}$ and by a number of other frameworks (ICAS, SST, FTK). The first three risk categories are addressed in-depth in Pillar I of the Solvency II framework, both in the standard and the internal models approaches. For these risk types, the risk-sensitivity of internal models would naturally be higher than that of standard models. Hence, we would say that for these risk types, condition 2 is satisfied. An important issue is non-life and health risk as indicated above. We will discuss operational risk below.

Liquidity risk is absent from Pillar I, potentially because (1) there is no agreed method to adequately measure liquidity risk; (2) Solvency II focuses on the solvency position, which is distinct from the liquidity position - a sufficiently solvent insurer can still face liquidity problems and vice versa; (3) an insurer's financial business model is not based on a liquidity mismatch, which makes liquidity risk of marginal importance compared to banking; and (4) insurance supervisors do not provide the lender-of-last-resort protection that banking supervisors do. We note that Basel II does not include a liquidity risk charge in Pillar I. However, Pillar II could be a useful instrument to address this risk type.

Operational risk is a complex risk type. Driven by Basel II, banks have struggled hard to measure it and it is still under debate whether the capital requirements themselves will decrease the frequency or severity of operational risk events. It is, however, visible that within banking the attention for operational risk has increased during the early 2000s and this must have had a positive effect on banks' risk awareness. Within Solvency II, the standard approach formula for operational risk is relatively simple: a factor based on premiums and technical provisions. ${ }^{29}$ Both variables are merely an indicator of company-size rather than operational risk profile. It is clear that other indicators such as the internal control environment, which are hard to express in quantitative capital requirements, are also major predictors of operational losses. Hence, it is not clear whether operational risk is sufficiently reflected in the current Solvency II proposals (i.e. whether criterion 2 is satisfied). Based on the findings of Van den Tillaart, ${ }^{30}$ we believe that more complex calculations are not necessarily a better predictor of operational losses. Therefore, the current proposals adequately address operational risk capital although qualitative organisational requirements in all three Pillars that assess the internal control environment could improve the Solvency II framework's sensitivity to the risk of insurer insolvency.

Additionally, business or strategic risk $^{31}$ is also an important business driver as indicated by Kuritzkes and Schuermann. ${ }^{32}$ In addition to being a risk type without a clear-cut definition, it is also not obvious that business risk is a supervisor's concern.

\footnotetext{
28 IAA (2004).

${ }^{29}$ CEIOPS (2007a, p. 34).

${ }^{30}$ Van den Tillaart (2003).

${ }^{31}$ Doff (2007a).

${ }^{32}$ Kuritzkes and Schuermann (2006).
} 
Other stakeholders may have a better view of the viability of business strategies, such as shareholders. However, the importance of business risk for supervisors is confirmed by the Sharma report, ${ }^{33}$ which concludes that wrong strategic decisions often have frequently led to insurance company (near-) failures. These effects normally do not show in a 1-year time horizon that is focused on the Pillar I requirements of Solvency II. To that end, we suggest including in Pillar II a continuity analysis (proposed in the FTK $)^{34}$ to investigate the long-term consequences of strategic choices. Doff ${ }^{35}$ argues that instruments other than capital requirements may be more appropriate to address business risk.

To conclude, we think that the major financial risks are reflected in capital requirements and that the existing formulae are sufficiently risk-sensitive, except for non-life and health risk. However, there is an important area for further work in developing frameworks that assess (not necessarily measure in quantitative terms) a number of other risks such as liquidity risks, operational risks and business risks. Pillars II and III of the Solvency II framework are the most logical mechanisms to address these gaps.

\section{The risk-based capital charges (or weights) for each major type of risk should be proportional to their impact on the overall risk of insolvency}

Differences in the outcomes of the risk formulae should be consistent with their importance in explaining the insolvency risk of companies. In Solvency II, both the standard and the internal models approach to the SCR are supposed to calibrate the capital requirement into a 99.5 per cent Value-at-Risk. This means that each risk category is expressed in the amount of capital required to absorb the risk of insolvency up to a 99.5 per cent confidence level. By taking into account diversification in the aggregation process, the gross capital requirement is assumed to be 99.5 per cent Value-at-Risk as well. Therefore, we believe that Solvency II satisfies this criterion 3.

However, care is required in setting the parameters. Too high parameters for certain risk types could result in too high capital requirements and disproportional weighting of specific risks. However, the calibration of the standard approach is not final yet. As a result, we cannot assess this risk at the time of writing. The same holds for the internal model criteria and the application of supervisory overrides. Also, prudential model approval procedures for certain risk types might also lead to disproportional weighting of certain risks.

\section{The risk-based capital system should focus on identifying insurers that are likely to impose the highest costs of insolvency}

This criterion reflects the finding that larger insurance company failures may impose higher costs to the economy although the likelihood of occurrence may be lower. From

\footnotetext{
${ }^{33}$ Ashby et al. (2003).

${ }^{34}$ DNB (2004).

${ }^{35}$ Doff (2007b).
} 
the perspective of the regulator and supervisor, the objectives of insurance regulation should be to limit failure costs to the (macro) economy rather than avoid all failures. From the perspective of an individual insurance company, the impact of an insolvency on the economic system may be irrelevant and the focus could be on the insolvency threshold only.

At this moment, the SCR is based on a 99.5 per cent Value-at-Risk measure. The 99.5 per cent confidence level itself already indicates that a certain number of insurance failures are tolerated. The QIS2 specifications for the standard approach included a socalled "size factor" to reflect the size diversification that would result in relatively lower capital requirements for larger companies. ${ }^{36}$ This is clearly against the finding that while larger companies might have a lower likelihood to fail, the costs of failure to the economy are higher. Therefore, the size factor does not satisfy criterion 4 . The so-called size factor has been dropped in QIS3, although for slightly different reasons. ${ }^{37}$

The Value-at-Risk determines the financial threshold beyond which a company is insolvent. It does not, however, address the size of the loss beyond the threshold, that is, the severity of the insolvency. The risk measure Tail-Value-at-Risk (Tail-VAR, also called Expected Policyholder Deficit, EPD, and Expected Shortfall ${ }^{38}$ better addresses this phenomenon. In addition, it has certain desirable mathematical characteristics such as subadditivity. ${ }^{39}$ By choosing Value-at-Risk as the central risk measure rather than Tail-VAR, Solvency II does not satisfy criterion 4. This suggests a conceptual preference for Tail-VAR over Value-at-Risk for regulatory purposes. In practice, solvency regimes differ in the choice for the risk measure: SST applies Tail-VAR whereas FTK applies Value-at-Risk.

The European Commission has decided to focus on a Value-at-Risk measure for Solvency II. ${ }^{40}$ The major consideration is that Value-at-Risk is more practicable for companies and that the more complex Tail-VAR probability distributions become less stable at extreme values, ${ }^{41}$ although Value-at-Risk seems theoretically less correct (see also criterion 7). Barth ${ }^{42}$ correctly remarks that Tail-VAR only addresses the direct insolvency costs: "Indirect insolvency costs, such as the cost of market disruptions in the wake of an insolvency, are an important consideration in the design of a regulatory risk-based capital system". 43 Therefore, although conceptually better than Value-atRisk, even Tail-VAR does not satisfy criterion 4. This makes the European Commission's choice for Value-at-Risk even more defendable.

Because this does not satisfy criterion 4, we see a clear role for other (potentially less quantitative) tools for supervisors to assess the potential costs of an insurance failure

\footnotetext{
${ }^{36}$ CEIOPS (2006)

${ }^{37}$ It was stated that the size factor puts smaller companies at an unfair competitive disadvantage compared to larger companies. CEA (2006).

${ }^{38}$ Butsic (1994), Barth (2000).

39 Artzner et al. (1999).

${ }^{40}$ Voluntarily, companies are allowed to choose for a Tail-VAR in the internal models approach.

${ }^{41}$ We personally understand the desire of the European Commission to minimise complexity as much as possible.

42 Barth (2000).

43 Ibid., p. 404.
} 
to the economy. For example, the ladder of intervention for Pillars II and III provides many opportunities to fill this gap. The objective of Pillar III requirements could be to decrease the information asymmetry between the managers and the policyholders. In case of a crisis, the role of Pillar II for supervisors and the company is to jointly and swiftly restore the situation.

5. The formula and/or the measurement of actual capital should reflect the economic values of assets and liabilities whenever practicable

Solvency II is focused on market-consistent valuation of assets and technical provisions, and hence of capital. Among others, the Sharma Report ${ }^{44}$ indicates the advantages of an economic valuation system compared to the traditional prudent historic cost philosophy. The insurance industry clearly supports a system based on risk-sensitive capital requirements and market consistent valuation principles (the so-called risk-based economic approach).$^{45}$ Earlier discussions ${ }^{46}$ about the exact methodology to calculate the market-consistent value of insurance liabilities have converged into the so-called cost-of-capital approach to measure non-hedgeable risks. ${ }^{47}$

However, full convergence with the accounting regulations (i.e. International Financial Reporting Standards (IFRS)) is not yet in place. Also, it is not yet fully clear whether accounting regulations will apply a full fair value paradigm at all. Major areas in which the accountants and the supervisors may diverge are the so-called exit value and the concept of profit at inception. ${ }^{48}$ If the future accounting regime will not apply full market-consistent techniques for insurance liabilities, ${ }^{49}$ it may very well be that the measurement of the balance sheet for IFRS purposes is not fully based on economic principles, that is, criterion 5 is not satisfied. Therefore, an additional choice needs to be made whether Solvency II will adopt the IFRS as a valuation basis or whether Solvency II and IFRS will exist in parallel.

6. To the extent possible, the risk-based capital system should discourage underreporting or loss of reserves and other forms of manipulations by insurers

We notice that the original authors ${ }^{50}$ discuss this issue only relatively briefly. In these modern times of accounting fraud, we agree that it is important that incentives for misreporting be minimised. Important elements within Solvency II are corporate governance, on-site monitoring powers and Pillar II. At this stage, it is too early to assess the effectiveness of the proposals.

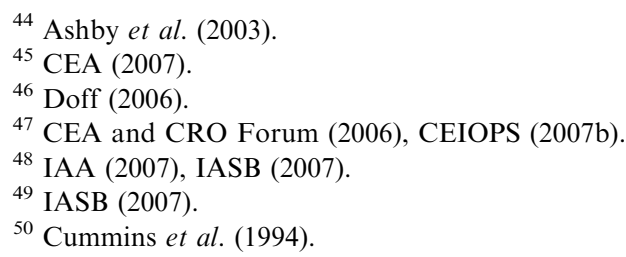




\section{The formula should avoid complexity that is of questionable value in increasing accuracy of risk measurement}

This criterion questions (unnecessary) complexity in the context of providing incentives to companies to manage their risks and avoid high insolvency costs for the economy. The overall structure of Solvency II is a widely accepted framework that combines capital requirements in Pillar I with supervisory review and market discipline in Pillars II and III, respectively. Also the option for companies to use internal models is a widely accepted supervisory principle. ${ }^{51}$ Although adding complexity to the system, this provides so much value to the system that it is acceptable and even desirable.

To comply with Solvency II, insurers will need to deal with certain qualitative organisational requirements in all Pillars. An example is the criterion for internal control and risk management governance structure. A similar structure exists in Basel II. However at this moment, little is known about the exact nature of these requirements in Solvency II. This means that we are neutral about whether Solvency II satisfies criterion 7 on this issue.

Under Solvency II, valuation of technical provisions will become more complex than under Solvency I. Examples are the discounting of non-life liabilities and the market-consistent valuation of options and guarantees. These elements are useful complexities because they more accurately predict the future claims payments to clients. In addition, adequate estimation of insurance liabilities will be an incentive for companies to appropriately price all product features into the product. To that end, criterion 7 is satisfied for the valuation of insurance liabilities.

An area of concern is the standard approach for the SCR. An internal model can be adapted to a specific company and hence the company itself can choose the desired complexity when designing the models. ${ }^{52}$ However, the standard model will need to be applied to a wide range of insurers, including specialised monoline companies and small companies. This means that care is required to add complexity that provides no additional value in incentivising companies and increasing accuracy of the results. We have already mentioned the European Commission's pragmatic preference for Value at-Risk over Tail-VAR (cf. criterion 4). Generally, the possibility of scenarios gives flexibility to companies to choose the appropriate level of complexity (similar to the internal models approach). Firstly, however, in the credit risk module there is no scenario-based approach. Here, the approach is based on the Basel II formula combined with the Herfindahl-index. Although theoretically potentially more correct, the increasing accuracy is doubtful.

Secondly, the long data history required in the non-life risk modules will be most often too complex for companies without substantially increasing accuracy and improving incentives. The long required data history could distract from recent trends. This could even punish innovative markets and markets with recent waves of privatisation.

\footnotetext{
${ }^{51}$ IAIS (2007).

${ }^{52}$ As indicated, little is yet known about the qualitative and organisational criteria to apply internal models.
} 
Table 1 Summary of results

\begin{tabular}{ll}
\hline Criterion & Assessment of solvency II \\
\hline 1. Getting the & Objective of solvency II satisfies criterion 1 \\
appropriate incentives & Internal models satisfy criterion 1 \\
& Not all standard approach elements provide desirable incentives (non-life/ \\
health risk). There is a role for pillar II \\
SCR as hard limit does not satisfy criterion 1. The SCR should be a target \\
value, supported by pillar II measures \\
Modular MCR does not satisfy criterion 1 and should be replaced by the \\
compact MCR approach
\end{tabular}

2. Formulae should be risk-sensitive

3. Formulae should be appropriately calibrated

4. Focus on the highest insolvency costs for economy as a whole

5. Focus on economic values

6. System should discourage misreporting

7. Simple formula as possible
Most formulae in standard approach are risk-sensitive, with exception of non-life and health risk

Operational risk capital sufficiently risk-sensitive. Further work in all three Pillars to develop organisational requirements (corporate governance)

Liquidity and business risk not addressed. Should be addressed in pillars II and III

Value-at-risk (99.5 per cent, 1 year) as reference point, satisfies criterion 3 Diversification is recognised, satisfies criterion 3

Too high parameters or too harsh internal model approval processes do not satisfy criterion 3

Value-at-Risk rather than Tail-VAR as risk measure does not satisfy criterion 4. Even Tail-VAR does not satisfy criterion 4. Should be addressed in pillar II and III

Market-consistent valuation techniques for Solvency II satisfy criterion 5

? Potential problems when Solvency II and accounting diverge

-Too early to assess-

More complex valuation of insurance liabilities adds value, satisfies criterion 7

Generally, the three-pillar structure of Solvency II framework with multiple approaches satisfies criterion 7

Standard approach SCR includes questionable complexity and data requirements, violates criterion 7

Table 1 summarises the results of our analysis in this section. We conclude that the objective of Solvency II satisfies most of the criteria. However, in the details some concerns remain, such as the risk modules of the standard approach (non-life and health risk), the treatment of the SCR and the approach to MCR.

As indicated the focus so far has been on Pillar I of the framework. We note that one of the objectives of supervision is to decrease the information asymmetry between stakeholders. Pillars II and III can play an important role in this process. Therefore, we have indicated in Table 1 where areas for further work could focus on those Pillars. 


\section{Concluding remarks}

Solvency II is the reform project for insurance supervision. In this paper, we have analysed the Solvency II framework as it is currently proposed by the European Commission. From the perspective of the economy, the focus of an insurance supervision framework should be to decrease information asymmetries and to align incentives for policyholders and the insurance company. Supervision should aim to minimise costs of insurance insolvencies to the economy as a whole rather than to limit insolvencies per se.

We have tested the proposed Solvency II framework against the criteria developed by Cummins et al. ${ }^{53}$ Generally, Solvency II satisfies these criteria as indicated in our paper. However, we identified some concerns. We recommend a more balanced framework between Pillars I and II/III, respectively. This could increase the efficiency of the Solvency II framework. These Pillars should focus on hard-to-quantify risks such as operational and business risks and long-term effects of strategic decisionmaking (e.g. continuity test). For these issues, Pillar II could focus on the corporate governance structures in place to ensure sufficiently thorough decision-making (cf. the findings of the Sharma report). Also, the issues related to size of insurance failure should be addressed in Pillar II. This ensures a focus on risks that can damage an insurance economy rather than one single (small) insurance company. Ultimately this increases the efficiency of a supervisory framework.

In the context of Pillar I, we raised a concern that treating the SCR as a hard limit will trigger suboptimal behaviour. Also, the Modular MCR is problematic and should be replaced by the Compact MCR. Finally, the complexity of some standard approach SCR components includes complexity without additional value in incentivising companies to apply good risk management.

\section{References}

Artzner, P., Delbaen, F., Eber, J.-M. and Heath, D. (1999) 'Coherent measures of risk', Mathematical Finance 9: 203-228.

Ashby, S., Sharma, P. and McDonnell, W. (2003) Lessons about risk: Analysing the causal chain of insurance company failure, Working Paper, Financial Services Authority, London.

Barth, M.M. (2000) 'A comparison of risk-based capital standards under the expected policyholder deficit and the probability of ruin approaches', Journal of Risk and Insurance 67: 397-414.

Basel Committee on Banking Supervision (2004) International Convergence of Capital Measurement and Capital Standards: A Revised Framework, Bank for International Settlements, Basel (June).

Butsic, R.P. (1994) 'Solvency measurement for property liability risk based capital applications', Journal of Risk and Insurance 61: 656-690.

Comité Européen des Assurances (CEA) (2006) CEA Preliminary Feedback on QIS2, ECO 6279, CEA (16 October).

Comité Européen des Assurances (CEA) (2007) Solvency II: Main results of CEA's impact assessment, CEA (June), pp. 1-28.

Comité Européen des Assurances (CEA) and Chief Risk Officer (CRO) Forum (2006) Solutions to major issues for Solvency II: Joint submission by the CRO Forum and CEA, CEA and CRO Forum (17 February).

\footnotetext{
${ }^{53}$ Cummins et al. (1994).
} 
Committee of Insurance and Occupational Pension Supervisors (CEIOPS) (2006) Quantitative Impact Study 2 - Technical specifications, CEIOPS, Frankfurt (May).

Committee of Insurance and Occupational Pension Supervisors (CEIOPS) (2007a) Quantitative Impact Study 3 - Technical Specifications, part I, CEIOPS, Frankfurt (April).

Committee of Insurance and Occupational Pension Supervisors (CEIOPS) (2007b) Pillar I Issues - Further Advice, CEIOPS, document-08-07, Frankfurt (March).

Cummins, D., Harrington, S. and Niehaus, G. (1994) 'An economic overview of risk-based capital requirements for the property-liability industry', Journal of Insurance Regulation 11: 427-447.

De Nederlandsche Bank (DNB) (2004) Consultatiedocument Financieel Toetsingskader, De Nederlandsche Bank (October).

Doff, R.R. (2006) Risk management for insurance firms: A framework for fair value and economic capital, Twente University.

Doff, R.R. (2007a) Risk Management for Insurers: Risk Control, Economic Capital and Solvency II, London: Risk Books.

Doff, R.R. (2007b) Defining and measuring business risk in an economic capital framework, working paper.

Eling, M., Schmeiser, H. and Schmit, J. (2007) 'The Solvency II process: Overview and critical analysis', Risk Management and Insurance Review 10: 69-85.

European Commission (2007) Proposal for new solvency requirement for insurance undertakings (Solvency II), Proposal for a Directive of the European Parliament and of the Council on the taking-up and pursuit of the business of Insurance and Reinsurance, COM (2007) 361 final.

Federal Office of Private Insurance (FOPI) (2004) Whitepaper of the Swiss Solvency Test, FOPI, Bern (November).

Financial Services Authority (FSA) (2004) Interim Prudential Sourcebook, London: FSA.

Financial Services Authority (FSA) (2005) ICAS: One year on, Insurance Sector Briefings, FSA, London (November).

International Accounting Standards Board (IASB) (2007) Preliminary views on insurance contracts, discussion paper, IASB, London (May).

International Actuarial Association (IAA) (2004) A Global Framework for Insurer Solvency Assessment, research report, Insurer Solvency Assessment Working Party, IAA, Ottawa.

International Actuarial Association (IAA) (2007) Measurement of liabilities for insurance contracts: Current estimates and risk margins, Exposure draft prepared by the Risk Margin Working Group, IAA, Ottawa (Feb. 23).

International Association of Insurance Supervisors (IAIS) (2003) Insurance core principles and methodology, IAIS, Basel, approved October 2003.

International Association of Insurance Supervisors (IAIS) (2007) The IAIS common structure for the assessment of insurer solvency, IAIS, Basel (February).

Klein, R.W. (1995) 'Insurance regulation in transition', Journal of Risk and Insurance 62: 363-404.

KPMG (2002) Study into the methodologies to assess the overall financial position of an insurance undertaking from the perspective of prudential supervision, KPMG (May).

Kuritzkes, A. and Schuermann, T. (2006) 'What we know, don't know and can't know about bank risk: A view from the trenches', in F.X. Diebold, R.J. Herring (eds) The Known, the Unknown and the Unknowable in Financial Risk Management, Princeton, NJ: Princeton University Press.

Sijben, J.J. (2002) 'Regulation versus market discipline in banking supervision: An overview - part 2', Journal of International Banking Regulation 4: 55-71.

Tillaart van den, A. (2003) Controlling Operational Risk: Concepts and Practices Twente University.

\section{About the Author}

R.R. Doff received his Ph.D. in July 2006 at Twente University on the subject of Risk Management for Insurance Firms. In addition, he works for Eureko, the largest insurance group in the Netherlands. He has published several books and papers on Risk Management. 